\title{
Titania Nanosheets (TNS)/Sulfonated Poly Ether Ether Ketone (SPEEK) Nanocomposite Proton Exchange Membranes for Fuel Cells ${ }^{\dagger}$
}

\author{
Debora Marani, ${ }^{*}, \S$ Alessandra D’Epifanio, ${ }^{\star}$ Enrico Traversa, ${ }^{\star, \perp}$ Masaru Miyayama, ${ }^{\S}$ and \\ Silvia Licoccia*, \\ *Department of Chemical Science and Technology \& NAST Centre for Nanoscience, Nanotechnology \& \\ Innovative Instrumentation, University of Rome Tor Vergata, Via della Ricerca Scientifica, 00133 Rome, \\ Italy, ${ }^{\S}$ Research Center for Advanced Science and Technology, The University of Tokyo, 4-6-1, Meguro-ku, \\ Tokyo 153-8904, Japan, and ${ }^{\perp}$ International Center for Materials Nanoarchitectonics (MANA), National \\ Institute for Materials Science (NIMS), 1-1 Namiki, Tsukuba, Ibaraki 305-0044, Japan
}

\section{Received August 5, 2009. Revised Manuscript Received November 25, 2009}

\begin{abstract}
Sulfonated polyetheretherketone (SPEEK)-based composite membranes containing various amounts of titania nanosheets (TNS) as inorganic filler have been prepared and investigated for proton exchange membrane applications. The SPEEK degree of sulfonation was DS $=0.58$ and the TNS content was in the range $0.95-10.00 \mathrm{wt}$. \% . The two-dimensional titanium oxide sheets, have been prepared as stable colloidal suspensions produced by the action of a quaternary ammonium ion, such as tetrabutylammonium, $\mathrm{TBA}^{+}$. SPEEK/TNS composites have been prepared by casting from DMA (dimethylacetamide). The samples have been characterized in terms of thermal stability (TG/ DTA, DSC), proton exchange capacity (P.E.C., by titration), water uptake, proton conductivity (EIS), and structural (XRD) and microstructural (SEM) features. Acid treated composites, at the lowest inorganic additive contents, exhibited improved properties in terms of proton conductivity and water uptake with respect to pure SPEEK. The best performing nanocomposite was the membrane containing only $1.67 \mathrm{wt} . \%$ TNS showing conductivity value of $4.1410^{-2} \mathrm{Scm}^{-1} \mathrm{at}^{-}$ $140{ }^{\circ} \mathrm{C}$ and at $100 \%$ of relative humidity $(\mathrm{RH})$, whereas pure SPEEK membrane exhibited a value of $1.76 \times 10^{-2} \mathrm{Scm}^{-1}$ at the same temperature and $\mathrm{RH}$ conditions. The volume swelling (VS), measured at $90{ }^{\circ} \mathrm{C}$ for the composite membrane containing $1.67 \mathrm{wt} . \%$ TNS, was reduced by ca. $80 \%$ with respect to that of a reference SPEEK membrane. The improved electrochemical properties of TNS nanocomposites have been associated to the unique nature of the two-dimensional nano structured inorganic additive.
\end{abstract}

\section{Introduction}

Proton exchange membrane fuel cell (PEMFC) technology is a promising, environmentally friendly energy production method alternative to fossil fuel combustion. ${ }^{1}$ The heart of the fuel cell is the polymeric electrolyte, which ensures the separation between anode and cathode and mediates the electrochemical reactions by transporting protons. The most common solid polymer electrolytes used in fuel cells are ionomers in their protonated form, such as Nafion and sulfonated hydrocarbons. ${ }^{2}$ Among the shortcomings of the ionomer-based PEMFC technology, important ones are related to conductivity failure at temperatures above $100{ }^{\circ} \mathrm{C}$ and electrolyte permeability to reactants, which causes fuels crossover through the membrane. ${ }^{3}$ In recent decades, great interest has been

\footnotetext{
'Accepted as part of the 2010 "Materials Chemistry of Energy Conversion Special Issue".

*Authors to whom correspondence should be addressed. Phone: +39-067259-4386 (S.L.); +39-06-7259-4062 (D.M.). Fax: +39-06-7259-4328 (S.L.); +39-06-7259-4328 (D.M.). E-mail: licoccia@uniroma2.it (S.L.); debora. marani@uniroma2.it (D.M.).

(1) Epping, K. M.; Kopasz, J. P. Fuel Cells 2009, 9, 356.

(2) Jones, D. J.; Rozière, J. Adv. Polym. Sci. 2008, 215, 219-264.

(3) Einsla, M. L.; Kim, Y. S.; Hawley, M.; Lee, H.-S.; McGrath, J. E.; Liu, B.; Guiver, M. D.; Pivovar, B. S. Chem. Mater. 2008, 20, 5636.
}

focused on the development of improved and inexpensive PEMs which could operate the cell under increased operating temperature $\left(120-130{ }^{\circ} \mathrm{C}\right)$ and/or low humidity level $(20 \leq \mathrm{RH} \leq 50 \%)$ to reduce the poisoning effect of carbon monoxide on platinum-based electro catalyst and increase the efficiency of the whole system. ${ }^{2,3}$

Among the several strategies explored, the dispersion of hygroscopic inorganic fillers into the polymeric matrix to fabricate organic-inorganic composite membranes has attracted much interest. ${ }^{2-5}$ These membranes have been specifically designed to promote internal self-humidification effects that can increase polymeric electrolyte water retention properties and ease water management even at high temperature and low humidity conditions. The improvement of hydration properties is a critical issue in the development of new generation polymeric electrolytes since proton conduction is a water-assisted mechanism. The composite membrane strategy has demonstrated to be effective in improving interesting polymer properties, such as proton conductivity, hydration, thermal,

(4) Thomassin, J. M.; Pagnoulle, C.; Bizzari, D.; Caldarella, G.; Germain, A.; Jerome, R. Solid State Ionics 2006, 177, 1137.

(5) Licoccia, S.; Traversa, E. J. Power Sources 2006, 159, 12. 
and mechanical stability. ${ }^{5-9}$ A variety of ceramic compounds, such as titania, silica, and zirconia, have already been used as fillers. ${ }^{2,3,5-13}$ The observed improvements are clearly related to the polymer/inorganic phase interfacial properties. In detail, the higher the interface interaction between the polymer and the dispersed particles, the greater is the filler influence on the original characteristics of the polymer. ${ }^{9,14}$ Nanoparticles are expected to modify the original characteristics to a greater extent than microparticles because of their larger specific surface area. When anisotropic fillers are used, the aspect ratio (AR, the ratio between the highest lateral dimension and the thickness of the elementary host layers) also influences composites characteristics. ${ }^{15}$ As a consequence, numerous research efforts have been focused on the development of composite electrolytes having nanostructured oxides as fillers. Nanostructured materials can be classified by their morphologies starting from the threedimensional (3D) spherical particles (e.g., powder materials), going through two-dimensional (2D) lamellae (e.g., exfoliated clay or nanosheets), to one-dimensional (1D) materials (nanofibers or nanotubes). ${ }^{15}$

Polymer matrix based nanocomposites containing exfoliated clay, carbon nanotubes, carbon nanofibers, exfoliated graphite (graphene), have been studied with the aim of improving mechanical properties and stability. ${ }^{16-19}$ Additionally, for fuel cell application 2D nanostructures have been attracting attention as fillers because of their large specific surface area and anisotropic structure that could be important in reducing fuel crossover. ${ }^{11,20}$

As far as the electrolyte polymeric matrix is concerned, a great number of polymers have been investigated. Some of these materials, especially the sulfonated hydrocarbons, show interesting features for possible high-temperature operation. ${ }^{2,3}$ We have been focusing our attention on sulfonated poly ether ether ketone (SPEEK)

(6) Wieser, C. Fuel Cells 2004, 4, 245

(7) Alberti, G.; Casciola, M.; Pica, M.; Tarpanelli, T.; Sganappa, M. Fuel Cells 2005, 5, 366.

(8) Watanabe, M.; Uchida, H.; Emori, M. J. Electrochem. Soc. 1998, $145,1137$.

(9) Su, Y.-H.; Liu, Y.-L.; Wang, D.-W.; Lai, J.-Y.; Guiver, M. D.; Liu, B. J. Power Sources 2009, 194, 206.

(10) Jung, D. H.; Peck, S. U.; Shin, D. R.; Kim, J. S. J. Power Sources 2003, 118, 205.

(11) Hogarth, W. H. J., Diniz da Costa, J. C., Lu, G. Q. (Max) J. Power Sources 2005, 142, 223.

(12) Baglio, V.; Di Blasi, A.; Aricò, A. S.; Antonucci, V.; Antonucci, P. L.; Trakanprapai, C.; Esposito, V.; Licoccia, S.; Traversa, E. J. Electrochem. Soc. 2005, 152, A1373.

(13) Baglio, V.; Aricò, A. S.; Di Blasi, A.; Antonucci, V.; Antonucci, P. L.; Licoccia, S.; Traversa, E.; Serraino Fiory, F. Electrochim. Acta 2005, 50, 1241.

(14) Alberti, G.; Casciola, M. Annu. Rev. Mater. Res. 2003, 33, 129.

(15) Kumar, A. P.; Depan, D.; Tomer, N. S.; Singh, R. P. Prog. Polym. Sci. 2009, 34, 479 .

(16) Woo, E.; Hugh, J.; Jeong, Y. G.; Skin, K. Phys. Rev. Lett. 2007, 98 , 136103.

(17) Guerin, G.; Prud'homme, R. E. J. Polym. Sci., Part B: Polym. Phys. 2007, 45, 10

(18) Lee, H.-S.; Fasulo, P. D.; Rodgers, W. R.; Paul, D. R. Polymer 2005, 46, 11673 .

(19) Matos, R. B.; Santiago, I. E.; Fonseca, C. F.; Linardi, M.; Lavayen, V; Lacerda, G. R.; Ladeira, O. L.; Ferlauto, S. A. J. Electrochem. Soc. 2007, 154, B1358.

(20) Kuan, H.-C.; Wu, C.-S.; Chen, C.-Y.; Yu, Z.-Z.; Dasari, A.; Mai, Y.-W. J. Electrochem. Solid-State Lett. 2006, 9, A76. based electrolytes. ${ }^{5}$ PEEK itself is a thermoplastic polymer characterized by high oxidative resistance, and high chemical, thermal, and mechanical stability. To achieve the correct electrochemical and mechanical properties, we have investigated SPEEK based hybrid materials, including both Class I hybrids, $, 13,21,22$ or composites, obtained dispersing inorganic compounds into the polymeric network, and Class II hybrids, ${ }^{23-26}$ where the inorganic network is covalently bound onto the polymer backbone.

Proton conductivity strongly depends on the polymer degree of sulfonation (numer of sulfonic groups per repeat polymer unit, DS): at low DS the hydrophilicity of the polymers is too low to reach the water content needed to attain adequate proton conductivity values to use the membrane as electrolyte in fuel cells applications, ${ }^{27}$ whereas if the DS is too high, the membrane presents excessive swelling and eventually becomes watersoluble. ${ }^{27,28}$ The addition of a nonintrinsically conducting inorganic component may cause a decrease on conductivity but it is known to limit swelling under high humidification conditions. ${ }^{2}$

To improve the thermal, physicochemical, and electrochemical properties of SPEEK-based membranes we investigated the effect of titania nanosheets (TNS) as inorganic filler. The polymer DS was set at 0.58 with the aim of reaching a compromise between the requirements of high proton conductivity and reduced swelling.

The structural formula of SPEEK having DS $=0.58$ is shown in Scheme 1.

\section{Experimental Section}

Materials. Polyetheretherketone (PEEK) was purchased in powder form from VICTREX (450 PF, $M_{\mathrm{w}}$ : $38300 \mathrm{~g} / \mathrm{mol}, 132$ repeat units per mole) and was used without any further purification.

The fibrous potassium tetratitanate $\mathrm{K}_{2} \mathrm{Ti}_{4} \mathrm{O}_{9} \cdot 1.9 \mathrm{H}_{2} \mathrm{O}$ was purchased by Otsuka Chemical. All the other chemicals (Wako Chemicals or Aldrich) were grade reagent and were used as received.

SPEEK Sulfonation. Sulfonated PEEK (DS = 0.58) was prepared as previously reported. ${ }^{25}$ Polymer samples were analyzed for proton exchange capacity (P.E.C.) and degree of sulfonation (DS) by titration and ${ }^{1} \mathrm{H}$ NMR. ${ }^{25}$

Titania Nanosheet (TNS) Preparation. Aqueous colloidal solutions of exfoliated TNS were prepared by chemically delaminating the layered starting material $\left(\mathrm{H}_{2} \mathrm{Ti}_{4} \mathrm{O}_{9} \cdot 1.9 \mathrm{H}_{2} \mathrm{O}\right)$ into its colloidal single layers upon action of an aqueous solution of

(21) Mecheri, B.; D’Epifanio, A.; Di Vona, M. L.; Traversa, E.; Licoccia, S.; Miyayama, M. J. Electrochem. Soc. 2006, 153, A463.

(22) Mecheri, B.; D'Epifanio, A.; Traversa, E.; Licoccia, S. J. Power Sources 2008, 178, 554

(23) Di Vona, M. L.; Marani, D.; D’Ottavi, C.; Trombetta, M.; Traversa, E.; Beurroies, I.; Knauth, P.; Licoccia, S. Chem. Mater. 2006, 18,69 .

(24) Marani, D.; Di Vona, M. L.; Traversa, E.; Licoccia, S.; Beurroies, I.; Liwellyn, P. L.; Knauth, P. J. Phys. Chem. B 2006, 110, 15817.

(25) Di Vona, M. L.; Marani, D.; D'Epifanio, A.; Traversa, E.; Trombetta, M.; Licoccia, S. Polymer 2005, 46, 1754.

(26) de Bonis, C.; D'Epifanio, A.; Di Vona, M. L.; D'Ottavi, C.; Mecheri, B.; Traversa, E.; Licoccia, S. Fuel Cells 2009, 9, 387.

(27) Zaidi, S. M. J.; Mikhailenko, S. D.; Robertson, G. P.; Guiver, M. D.; Kaliaguine, S. J. Membr. Sci. 2000, 173, 17.

(28) Mikhailenko, S. D.; Zaidi, S. M. J.; Kaliaguine, S. Catal. Today 2001, 67, 225. 
Scheme 1. Chemical Structure of SPEEK at DS $=0.58$, Showing Sulfonated an Unsulfonated Repeat Units

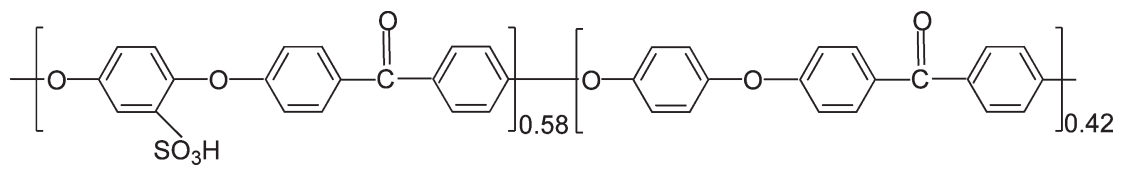

tetrabutylammonium hydroxide $(\mathrm{TBAOH}){ }^{29}$ The colloidal suspensions showed an opalescent color with a bluish tint. The $\mathrm{Ti}^{4+}$ concentration, obtained by ICP analysis, was $1.86 \mathrm{~g} / \mathrm{L}$.

Composite Membrane Preparation. Composite membranes with different TNS content, ranging from 0.95 up to $10.00 \mathrm{wt}$. $\%$, were prepared by solution casting mixing together the proper amount of TNS and SPEEK. TNS aqueous suspensions were first heated to $60{ }^{\circ} \mathrm{C}$ on a hot plate to reduce water excess. When the suspension volume was about $1 \mathrm{~mL}$, dimethylacetamide (DMA, $10 \mathrm{~mL}$ ) was added, and the resulting suspension was kept in an ultrasonic bath for $2 \mathrm{~h}$, and then stirred for $1 \mathrm{~h}$. The polymer $(250 \mathrm{mg})$ was dissolved in DMA $(20 \mathrm{~mL})$ at room temperature under stirring and the resulting solution was added to the TNS/DMA suspension. The resulting mixture was treated in an ultrasonic bath for $1 \mathrm{~h}$, kept stirring for $2 \mathrm{~h}$ at room temperature, and finally poured into a glass plate. The suspension was kept again under stirring at $80{ }^{\circ} \mathrm{C}$ reducing the volume to $2-3 \mathrm{~mL}$, then left at $60{ }^{\circ} \mathrm{C}$ until the solvent evaporated. Membranes were peeled off with water.

Pure SPEEK reference membranes $\left(C_{0}\right)$ were prepared by casting from DMA/SPEEK solution.

To separate the effect of the addition of $\mathrm{TBA}^{+}$from that of TNS to a SPEEK matrix, an additional reference membrane containing no TNS was prepared by cation exchange reaction on the polymer sulfonic groups. The polymer $(250 \mathrm{mg})$ was suspended in $10 \mathrm{wt} . \%$ TBAOH water solution (ca. $50 \mathrm{~mL}$ ) and the suspension was kept stirring at room temperature for $24 \mathrm{~h}$. The polymer was separated by filtration, washed with deionized water to remove excess TBAOH until neutral $\mathrm{pH}$, dried, then used to prepare the membrane, labeled $\mathrm{TBA}-\mathrm{C}_{0}$, following the above-described casting procedure.

Composite Membrane Treatments. Prior to any characterization, membranes were treated to remove DMA and TBAOH residuals. Two different procedures were carried out. In the first one, membranes were washed in water at room temperature for $24 \mathrm{~h}$, and then dried at $120^{\circ} \mathrm{C}$ in a vacuum oven for $24 \mathrm{~h}$. The water treated membranes were labeled $\mathrm{C}_{\mathrm{nTBA}}$ where $\mathrm{n}$ indicates the TNS content. The second treatment consisted in washing the composites with $0.5 \mathrm{~N} \mathrm{HCl}$ at $80{ }^{\circ} \mathrm{C}$ for a time ranging from 1 day up to 10 days depending on the amount of TNS colloidal suspension used. Acid membranes were washed with water to remove excess acid, then dried at $120{ }^{\circ} \mathrm{C}$ in a vacuum oven for $24 \mathrm{~h}$. The acid-treated nanocomposite membranes were labeled $C_{n \mathrm{~A}}$, where $n$ indicates the TNS content. The times of acid treatment were $24,48,72,120,168$, and $240 \mathrm{~h}$ for samples $C_{0.95 \mathrm{~A}}, C_{1.35 \mathrm{~A}}, C_{1.67 \mathrm{~A}}, C_{2.65 \mathrm{~A}}, \mathrm{C}_{5.33 \mathrm{~A}}$, and $\mathrm{C}_{10.00 \mathrm{~A}}$, respectively.

Materials Characterization. Atomic force microscopy (AFM) images were recorded using a Seiko Instruments SPI400 microscope. observations were carried out in tapping mode with silicon cantilever (force constant $20 \mathrm{~N} / \mathrm{m}$ ). The specimens were prepared by adsorbing titania nanosheets on cationic surface of ITO (indium-tin oxides) coated with a monolayer of polyelectrolyte (poly(diallyldimethylammonium chloride), PDDA). Deposition of single nanosheets can be achieved through electrostatic

(29) Suzuki, S.; Miyayama, M. J. Phys. Chem. B 2006, 110, 4731. self-assembly by dipping the coated substrate into the colloidal suspension $(0.08 \mathrm{~g} / \mathrm{L}, \mathrm{pH}$ 9) for $20 \mathrm{~min}$ followed by washing it with water. ${ }^{30}$

${ }^{1} \mathrm{H}$ nuclear magnetic resonance (NMR) spectra were recorded preparing DMSO- $\mathrm{d}_{6}$ solutions with a Bruker Avance 400 spectrometer. Chemical shifts ( $\mathrm{ppm})$ are referenced to tetramethylsilane (TMS).

Thermogravimetric analysis (TGA) was performed by using a Thermoplus TG 8120 apparatus (Rigaku, Japan) with a heating rate of $2 \mathrm{~K} / \mathrm{min}$ under air flux in platinum sample holders.

Differential scanning calorimetry (DSC) experiments were performed using a Thermoplus DSC apparatus (Rigaku, Japan) in the $25-230{ }^{\circ} \mathrm{C}$ temperature range, using aluminum sample holders under nitrogen flux with a heating rate of $10 \mathrm{~K} / \mathrm{min}$.

$\mathrm{X}$-ray diffraction (XRD) patterns were recorded at room temperature using a PW 1729 X-ray diffractometer (Philips International, Inc.) using $\mathrm{Cu} \mathrm{K} \alpha$ radiation. Data were collected by the step-scanning mode with steps of $0.05^{\circ}$ (time per step: $1 \mathrm{~s}$ ). Bragg's law, $\lambda=2 d \sin \theta$, was used to calculate the interlayer spacing $d$.

Field emission scanning electron microscopy (FE-SEM) observations were performed using a LEO (model Supra 35) instrument on sample cross sections. The cross sections were prepared by fracturing membranes in liquid nitrogen.

Proton exchange capacity (P.E.C.) was determined through an acid-base titration. The dry membranes, typically 100$150 \mathrm{mg}$, were immersed in $0.1 \mathrm{~N} \mathrm{NaOH}$ and kept under stirring for $24 \mathrm{~h}$, then back-titrated with $0.1 \mathrm{~N} \mathrm{HCl}$, following the $\mathrm{pH}$ variation using a digital pHmeter (Amel Instruments).

Water uptake (W.U.) was calculated as reported in the literature $^{22}$ using the following equation:

$$
\text { W.U. }=\left[\left(\frac{W_{\text {wet }}}{W_{\text {dry }}}\right)-1\right] \times 100
$$

where W.U. is expressed in percentage units, $W_{\text {wet }}$ is the weight of the wet membrane, and $W_{\text {dry }}$ is the weight of the dry membrane. The dry membranes were immersed in $20 \mathrm{~mL}$ of water and kept in water at different temperatures until the equilibrium was reached ( $\sim 5 \mathrm{~h}$ ), then dried with absorbent paper, and weighted. Following the same procedure, volume swelling (VS) was determined as the ratio between the volumes of the swelled and dry membrane for sample $C_{1.67 \mathrm{~A}}$ and for the reference pure SPEEK membrane $C_{0}$, in the temperature range between 20 and $90{ }^{\circ} \mathrm{C}$.

SSA of the nanosheets was estimated from XRD data using eq 2 using the unit cell dimensions reported in the literature: ${ }^{31}$

$$
\mathrm{SSA}=\frac{2}{\rho \times d}
$$

In eq 2, $\rho$ is the experimental value of the density for $\mathrm{H}_{2} \mathrm{Ti}_{4} \mathrm{O}_{9}$. $9 \mathrm{H}_{2} \mathrm{O}^{32}$ and $d$ is the interlayer distance be obtained by XRD analysis.

(30) Tanaka, T.; Fukuda, K.; Ebina, Y.; Takada, K.; Sasaki, T. Adv. Mater. 2004, 16, 872 .

(31) Alberti, G. In Two and Three-Dimensional Inorganic Networks, Comprehensive Supramolecular Chemistry Series; Alberti, G., Bein, T., Eds.; Pergamon: Elsevier Science, 1996; Vol. 7, p 164.

(32) Sasaki, T.; Watanabe, M.; Komatsu, Y.; Fujiki, Y. Inorg. Chem. 1985, 24, 2265. 
The SSA of any single sheet or lamella contained in a layered inorganic solid (such as $\mathrm{H}_{2} \mathrm{Ti}_{4} \mathrm{O}_{9} \cdot 1.9 \mathrm{H}_{2} \mathrm{O}$ ) can, in fact, be defined as the surface of $1 \mathrm{~g}$ of solid considered as a single giant lamella. ${ }^{31}$

Conductivity of the membranes at saturated water pressure was evaluated using electrochemical impedance spectroscopy (EIS) measurements, performed with a multichannel potentiostat VMP3 (Princeton Applied Research) at the oscillation amplitude of $0.1 \mathrm{~V}$ in the $10 \mathrm{~Hz}$ to $1 \mathrm{MHz}$ frequency range. The sample temperature was monitored using a thermocouple placed near the sample. The conductivity was calculated using the following equation:

$$
\sigma=\frac{L}{A} \times \frac{1}{R}
$$

where $L$ is the membrane thickness, $A$ is the surface area of the electrodes, and $R$ is the resistance derived from the measurements.

\section{Results and Discussion}

Nanosheet Characterization. The key step in nanosheet synthesis is the delamination of the layered precursor compound, typically by intercalation of bulky guest species. The action of a quaternary ammonium ion, such as $\mathrm{TBA}^{+}$, is effective in producing stable colloidal suspensions of negatively charged nanosheets $\left[\mathrm{TBA}_{\mathrm{x}}^{+}\left(\mathrm{H}_{2-x^{-}}\right.\right.$ $\left.\left.\mathrm{Ti}_{4} \mathrm{O}_{9}\right)^{x-}\right]^{29,30,33-35}$ Atomic force microscopy (AFM) allowed the identification of the individual nanosheet crystallites. Figure 1a shows the atomic force micrograph of the TNS film obtained by the self-assembly process. Thin sheets of approximately $400 \mathrm{~nm}$ in length and $100 \mathrm{~nm}$ in width were identified. The average thickness of the sheets (Figure 1b), averaged over several observations, was about $4 \mathrm{~nm}$, whereas the thickness of individual titania nanosheets quoted in literature is well below $1 \mathrm{~nm}$ (being reported to be around $0.75 \mathrm{~nm}$ ). ${ }^{36}$ The difference observed indicated that the colloidal suspension obtained and used for the composite preparation was not made of dispersed single nanosheets, but consisted in dispersed multilayer nanosheets, in agreement with what reported in a previous work. ${ }^{29}$

Important parameters, related to inorganic nano filler morphology, that are known to affect the extension, nature, and properties of the polymer/filler interface in nanocomposite systems are specific surface area (SSA) and aspect ratio (AR). The direct measurement of TNS SSA cannot be obtained experimentally, since the elementary TNS layers can exist in the form of single exfoliated sheets only in a liquid colloidal suspension. However, it is possible to estimate an empirical value of such parameter using the experimental XRD data $\left(\rho=3.006 \mathrm{~g} / \mathrm{cm}^{3}, d=\right.$ $0.91 \mathrm{~nm})$, the specific surface area of the TNS used in the present work resulted to be $735 \mathrm{~m}^{2} / \mathrm{g}$. Such value is

(33) Osada, M.; Ebina, Y.; Funakubo, H.; Yokoyama, S.; Kiguchi, T.; Takada, K.; Sasaki, T. Adv. Mater. 2006, 18, 1023.

(34) Fendler, J. H. Chem. Mater. 1996, 8, 1616.

(35) Sugimoto, W.; Terabayashi, O.; Murakami, Y.; Tasaku, Y. J Mater. Chem. 2002, 12, 3814.

(36) Takayoshi, S.; Nakano, S.; Yamauchi, S.; Watanabe, M. Chem. Mater. 1997, 9, 602 .
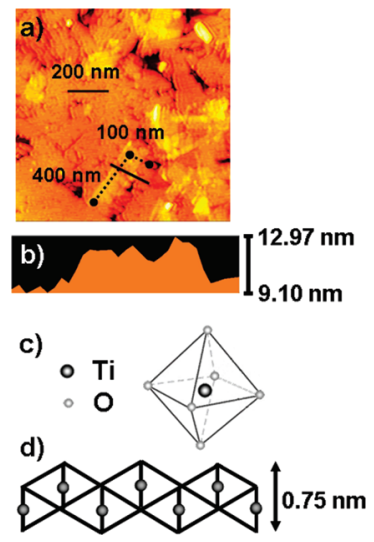

Figure 1. (a) Atomic force image of TNS deposited onto glass substrate by self-assembly process, (b) experimental thickness of TNS, (c) scheme of Ti atom octahedral coordination with six oxygen atoms, and (d) structure of the $2 \mathrm{D} \mathrm{Ti}_{0.87} \mathrm{O}_{2}$ nanosheet, resulting by joining through edge sharing the $\mathrm{TiO}_{6}$ octahedra. The thickness of the sheets, consisting of two edgeshared $\mathrm{TiO}_{6}$ octahedra, is well below $1 \mathrm{~nm} .^{36}$

consistent with those evaluated using eq 2 (see the Experimental Section) and reported for other intensively studied layered materials such as $\alpha$-zirconium phosphate $\left(976 \mathrm{~m}^{2} / \mathrm{g}\right)$ and mesoporous zirconium phosphate-pyrophosphate $\left(215 \mathrm{~m}^{2} / \mathrm{g}\right) .^{31,37}$ Several phenomena involved in nanocomposites preparation, including polymer intercalation, may reduce the filler active area, so that these values can be considered only as indicative. At variance, the AR can be experimentally measured and is of paramount importance when anisotropic fillers such as TNS are considered. In the present case, the values observed in the AFM image for the highest lateral dimension and the thickness of the TNS packets were 400 and $4 \mathrm{~nm}$, respectively, so that the calculated aspect ratio resulted to be $\mathrm{AR}=100$.

Composites Characterization. TNS/SPEEK composites having different filler content (from 0.95 to $10.00 \mathrm{wt}$ \% \%) were prepared by casting. Two series of samples were prepared: the first one (labeled $\left(C_{n \mathrm{TBA}}\right)$ was obtained keeping the membranes in water at room temperature for $24 \mathrm{~h}$ to remove the excess casting solvent (DMA) and TBAOH. The second set of samples (labeled $C_{\mathrm{nA}}$ ) was prepared by acid treating $C_{n \mathrm{TBA}}$ membranes. Membranes were acid treated until no trace of TBA decomposition was observed in the TG/DTG curves and until the $\mathrm{Tg}$ reached values close to that of pure SPEEK. Table 1 reports composition, thermal data, and P.E.C. of all the samples.

Figure 2 shows the DTG profiles (the derivative of the thermogravimentric curves) recorded for reference samples $C_{0}$ (pure SPEEK, trace a), TBA- $C_{0}$ (containing no TNS, trace b), composites $C_{1.67 \mathrm{TBA}}-C_{10.00 \mathrm{TBA}}$ (traces $\mathrm{c}-\mathrm{f}$ ), and composite $C_{10.00 \mathrm{~A}}$ (trace $\mathrm{g}$ ). The SPEEK decomposition process consists of two steps: a degradation stage, around $240-280{ }^{\circ} \mathrm{C}$, associated with the decomposition of sulfonic groups $\left(\mathrm{SO}_{3}{ }^{-}\right)$, and a second one, around $400-450{ }^{\circ} \mathrm{C}$ (not shown), due to the polymer main chain

(37) Alberti, G.; Casciola, M.; Marmottini, F.; Viviani, R. J. Porous Mater. 1999, 6, 299. 
Table 1. Glass Transition Temperature ( $T_{\mathrm{g}}$ ), P.E.C., and Decomposition Temperature of the Sulfonic Groups for Composite Membranes with Various TNS Contents

\begin{tabular}{lcccc}
\hline sample & $\begin{array}{c}\text { TNS content } \\
(\text { wt. } \%)\end{array}$ & $T_{\mathrm{g}}\left({ }^{\circ} \mathrm{C}\right)$ & $\begin{array}{c}\text { P.E.C. } \\
(\mathrm{meq} / \mathrm{g})\end{array}$ & $\begin{array}{c}\mathrm{SO}_{3} \\
\mathrm{dec} T\left({ }^{\circ} \mathrm{C}\right)\end{array}$ \\
\hline$C_{0}$ & 0 & 197 & 1.72 & 274 \\
TBA- $C_{0}$ & 0 & 135 & 0 & 266 \\
$C_{0.95 \mathrm{TBA}}$ & 0.95 & 186 & 0.94 & 274 \\
$C_{1.35 \mathrm{TBA}}$ & 1.35 & 184 & 0.83 & 274 \\
$C_{1.67 \mathrm{TBA}}$ & 1.67 & 169 & 0.44 & 274 \\
$C_{2.65 \mathrm{TBA}}$ & 2.65 & 154 & 0.31 & 266 \\
$C_{5.33 \mathrm{TBA}}$ & 5.33 & 140 & 0.22 & 267 \\
$C_{10.00 \mathrm{TBA}}$ & 10.00 & 139 & 0.10 & 268 \\
$C_{0.95 \mathrm{~A}}$ & 0.95 & 198 & 1.41 & 278 \\
$C_{1.35 \mathrm{~A}}$ & 1.35 & 200 & 1.45 & 280 \\
$C_{1.67 \mathrm{~A}}$ & 1.67 & 200 & 1.48 & 281 \\
$C_{2.65 \mathrm{~A}}$ & 2.65 & 200 & 1.54 & 283 \\
$C_{5.33 \mathrm{~A}}$ & 5.33 & 201 & 1.69 & 282 \\
$C_{10.00 \mathrm{~A}}$ & 10.00 & 203 & 1.75 & 285
\end{tabular}

pyrolysis. ${ }^{24}$ In the $250-310{ }^{\circ} \mathrm{C}$ temperature range, while $C_{0}$ showed only one decomposition process ascribable to the sulfonic group decomposition, an extra decomposition process around $300{ }^{\circ} \mathrm{C}$ was clearly detected for sample TBA- $C_{0}$ and for samples $C_{2.65 \text { TBA }}-C_{10.00 \text { TBA. }}$. Such peak, observed only for TBA containing composites, is associated to $\mathrm{TBA}^{+}$degradation. The only significant difference observed for sample $C_{1.67 \mathrm{TBA}}$ with respect to reference sample $C_{0}$ was a small shoulder related to the TBA decomposition process. The very low intensity of such shoulder and the invariance of the sulfonic group decomposition temperature can be explained on the basis of the very low content of TNS. The shift to lower temperatures observed for the decomposition peak of the sulfonic groups for all the other samples containing the $\mathrm{TBA}^{+}$cation (from $274{ }^{\circ} \mathrm{C}$ for pure SPEEK to $266^{\circ} \mathrm{C}$ for TBA- $C_{0}$ ) can be ascribed to the decrease in intermolecular interactions between sulfonic groups (ionomer effect) due to hydrogen bonding. ${ }^{27}$ Trace $\mathrm{g}$ in Figure 2 shows the DTG curve of the acid treated composite $C_{10.00 \mathrm{~A}}$. The acid treatment caused the disappearance of the peak due to TBA decomposition and a single decomposition step (centered at $285^{\circ} \mathrm{C}$ ), associated to sulfonic group degradation, was detected. The peak shifted to a higher temperature with respect to $C_{0}$. The sulfonic groups decomposition temperature of all acid treated samples is reported in Table 1 . The slight increase observed over the whole series with increasing TNS content (from $274{ }^{\circ} \mathrm{C}$ for $C_{0}$ to $285^{\circ} \mathrm{C}$ for $\left.C_{10.00 \mathrm{~A}}\right)$ indicated that a polar interaction occurred between the $\mathrm{SO}_{3} \mathrm{H}$ functions and the inorganic TNS phase.

Table 1 also reports the $T_{\mathrm{g}}$ values measured for the two series of tested composites. For $C_{n \text { TBA }}$ samples, a steady decrease in $T_{\mathrm{g}}$ (from $197{ }^{\circ} \mathrm{C}$ for $C_{0}$, to $139{ }^{\circ} \mathrm{C}$ for $C_{10.00 \mathrm{TBA}}$, to $135{ }^{\circ} \mathrm{C}$ for TBA- $C_{0}$ ) with increasing amount of TNS was observed. A monotonic decrease of $T_{\mathrm{g}}$ values with decreasing the content of acid moieties has been previously verified for SPEEK samples at different sulfonation degrees and attributed to the decrease of the ionomer effect and concomitant increase of segmental motions. ${ }^{27}$ The formation of the salt form

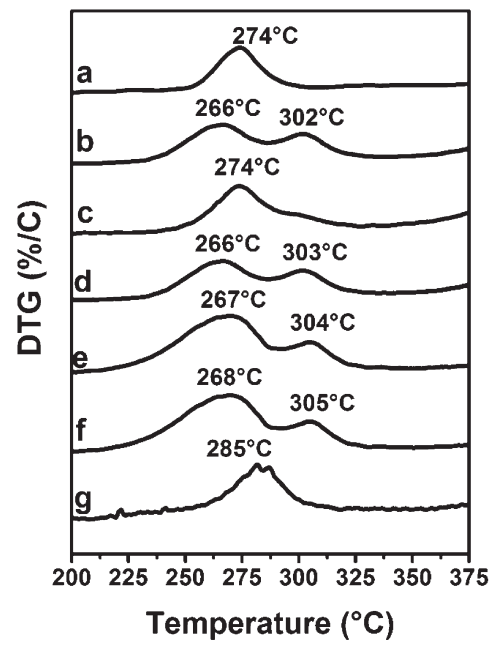

Figure 2. DTG profiles of composite membranes: (a) $C_{0}$, (b). TBA- $C_{0}$, (c) $C_{1.67 \mathrm{TBA}},(\mathrm{d}) C_{2.65 \mathrm{TBA}}$, (e) $C_{5.33 \mathrm{TBA}}$, (f) $C_{10.00 \mathrm{TBA}}$, and (g) $C_{10.00 \mathrm{~A}}$.

of SPEEK in the presence of the $\mathrm{TBA}^{+}$cation seems to have an effect analogous to the decrease of the polymer DS.

For the $C_{n \mathrm{~A}}$ series, $T_{\mathrm{g}}$ increases with TNS content (from $197{ }^{\circ} \mathrm{C}$ for $C_{0}$ to $203^{\circ} \mathrm{C}$ for $C_{10.00 \mathrm{~A}}$, Table 1) with a trend that parallels the one observed for the sulfonic groups decomposition temperature, thus confirming the existence of polar interactions between the polymer and nanostructured inorganic filler. The increase of $T_{\mathrm{g}}$ of SPEEK-based composites has been previously reported and attributed to restricted segmental motion of the polymer chains due polymer-filler to hydrogen-bonding interactions. ${ }^{38}$

Figure 3 shows typical XRD patterns of (a) $\mathrm{H}_{2} \mathrm{Ti}_{4} \mathrm{O}_{9}$. $1.9 \mathrm{H}_{2} \mathrm{O}$, (b) water treated $C_{10.00 \mathrm{TBA}}$, (c) acid treated $\mathrm{C}_{10.00 \mathrm{~A}}$, and (d) pure SPEEK, respectively. The XRD plots of the composites, both water and acid treated, showed the presence of peaks ascribable to a basal (200) $d$-spacing (related to the interlayer distance), due to the presence of an intercalated compound. ${ }^{30}$ This peak is in agreement with the $d$-spacing observed for $\mathrm{H}_{2} \mathrm{Ti}_{4} \mathrm{O}_{9} \cdot 9 \mathrm{H}_{2} \mathrm{O}$. These results excluded the presence of exfoliated single sheets dispersed into the polymeric matrix. Conversely, an in situ reassembling process leading to the formation of TNS packets upon the membrane preparation procedure is suggested. It is worth noticing that the $d$-spacing XRD peak for the nanocomposite membranes was observed at lower $2 \theta$ (or larger $d$-spacing) compared with that of the protonated starting material. This result indicates that the inter space among TNS has expanded as a possible consequence of polymer intercalation. ${ }^{39}$ Placing polymer chains in such confined space would involve a significant entropy penalty that presumably must be driven by an electrostatic interaction between the polymer and the inorganic filler. ${ }^{40} \mathrm{~A}$ key factor in the polymer-filler interaction, and consequent polymer intercalation phenomena, is the affinity between polymer

(38) Krishnan, P.; Park, J.-S.; Kim, C.-S. J. Membr. Sci. 2006, 279, 220. (39) Pavlidou, S.; Papaspyrides, C. D. Prog. Polym. Sci. 2008, 33, 1119. (40) Vaia, R. A.; Giannelis, E. P. Macromolecules 1997, 30, 8000. 


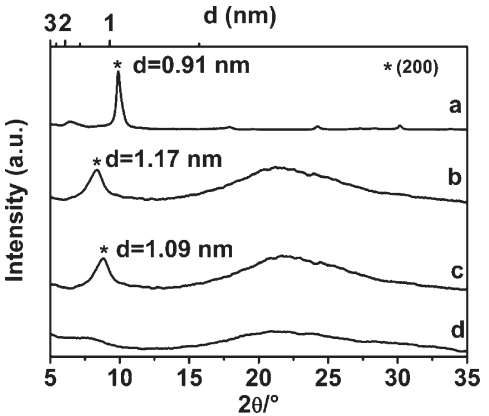

Figure 3. XRD patterns for (a) $\mathrm{H}_{2} \mathrm{Ti}_{4} \mathrm{O}_{9}$, (b) $\mathrm{C}_{10.00 \mathrm{TBA}}$, (c) $\mathrm{C}_{10.00 \mathrm{~A}}$, and (d) $\mathrm{C}_{0}$.

segments and the inorganic species surface. ${ }^{39-44}$ In such context, an essential role is clearly played by the polar nature of the components. The electrostatic interactions among the polar polymeric groups (acid moieties and carbonyl functions) and the negatively charged titania nanosheets is the driving force for the in situ reassembling process. On the other hand, the above-mentioned affinity is expected also to significantly affect the adhesion of the filler to the polymeric matrix. The greater the chemical affinity, as in the case of polar polymer chains and charged nanosheets, the larger the polymer-filler adhesion and the interfacial interactions. ${ }^{39-44}$

As expected, the P.E.C. of the membranes decreases dramatically as a function of TBA content in the $C_{n \text { TBA }}$ series of composites (Table 1), as a result of the decrease of the number of protons available to ionic exchange. For the acid treated composites, $\mathrm{C}_{n \mathrm{~A}}$, P.E.C. values showed a minimum for sample $C_{0.95 \mathrm{~A}}$, indicating that for this TNS composition the maximum adhesion between polymer and filler occurred and that the polar sites of the polymer are engaged in electrostatic interactions with TNS active sites. For larger TNS contents, P.E.C. increased up to the original value measured for reference $C_{0}$. Therefore, it seems that, above the 1 wt. $\%$ TNS concentration limit, the polar sites present on TNS surface give their own contribution to the proton exchange capacity creating additional sites for proton transfer.

Figure 4 shows the SEM micrographs of the cross sections of samples $C_{10.00 \mathrm{TBA}}$ (a) and $C_{10.00 \mathrm{~A}}$ (b). The high magnification images show the presence of an inorganic structure homogenously dispersed into the polymeric matrix. In detail, SEM images point out that nanosized TNS are present as nano packets with a total thickness of $\sim 60 \mathrm{~nm}$. The calculated filler aspect ratio is $\mathrm{AR} \approx 7$, that is, much lower than the value calculated from AFM data for pure TNS. The result confirms XRD analysis, demonstrating that TNS rearrange in the polymer matrix in packets of lamellae. However, the AR value is still much higher than that of an isotropic filler $(A R=1)$, so that the number of accessible functional sites on the surface of layers is very high, contributing to SPEEK-TNS

(41) Fornes, T. D.; Paul, D. R. Macromolucules 2004, 37, 7698.

(42) Fornes, T. D.; Paul, D. R. Macromolucules 2004, 37, 1793.

(43) Shah, R. K.; Kim, D. H.; Paul, D. R. Polymer 2007, 48, 1047.

(44) Kim, D. H.; Fasulo, P. D.; Rodgers, W. R.; Paul, D. R. Polymer 2007, 48, 5960 .

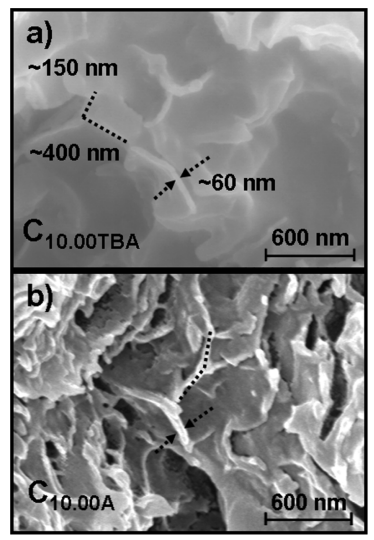

Figure 4. FE-SEM micrographs of the cross sections of (a) $C_{10.00 \mathrm{TBA}}$ and (b) $C_{10.00 \mathrm{~A}}$ at high magnification.

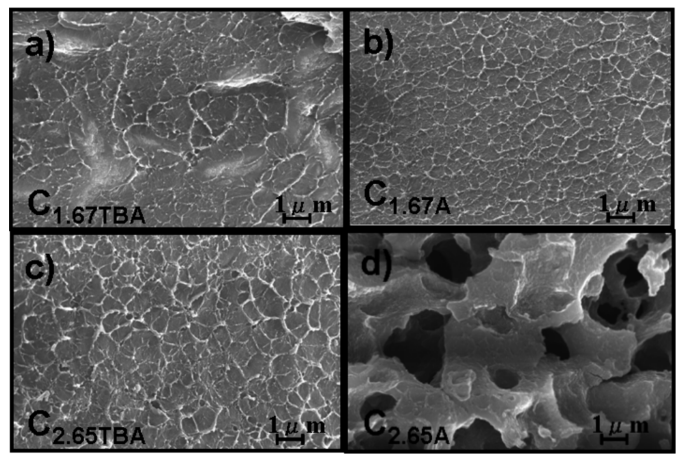

Figure 5. FE-SEM micrographs of the cross-section of (a) $C_{1.67 \mathrm{TBA}}$, (b) $C_{1.67 \mathrm{~A}}$, (c) $C_{5.33 \mathrm{TBA}}$, and (d) $C_{5.33 \mathrm{~A}}$.

adhesion phenomena and electrostatic interactions. For samples at lower filler concentration it was not possible to identify TNS in the SEM images, hence to calculate the filler AR. It is however reasonable to assume that the AR would be equal or greater than 7 , because the higher dilution of the nanosheets would limit their reassembling into packets. The porous morphology observed for sample $C_{10.00 \mathrm{~A}}$ might be originated from the prolonged acid treatment (10 days in refluxing $0.5 \mathrm{~N} \mathrm{HCl}$ ).

Since a dense morphology is an essential requirement for polymer electrolytes, a systematic SEM investigation was then performed on all the composites. Figure 5 shows the SEM micrographs of the composite membranes containing $1.67 \mathrm{wt}$. $\%$ and $5.33 \mathrm{wt}$. \% TNS, chosen as representative examples, before and after acid treatments. All the composites with smaller TNS contents $\left(C_{0.95 \mathrm{~A}^{-}}\right.$ $C_{2.65 \mathrm{~A}}$ ) showed the dense morphology required for their use as electrolytes, as shown in Figure 5a and $\mathrm{b}$ for samples $C_{1.67 \mathrm{TBA}}$ and $C_{1.67 \mathrm{~A}}$, respectively. On the contrary, a detrimental effect on morphology was observed for the composites with larger TNS concentrations. In fact, while pristine $C_{5.33 \text { TBA }}$ (Figure $5 \mathrm{c}$ ) was dense, the presence of a spread porosity is evident for the acid treated samples $\left(C_{5.33 \mathrm{~A}}\right.$, Figure $\left.5 \mathrm{~d}\right)$.

Figure 6a shows the water uptake of the acid treated TNS composites as a function of the temperature. The W.U. of composites progressively increased with TNS amount, being in any case larger than that of $C_{0}$. In detail, two different trends could be identified. For samples with 

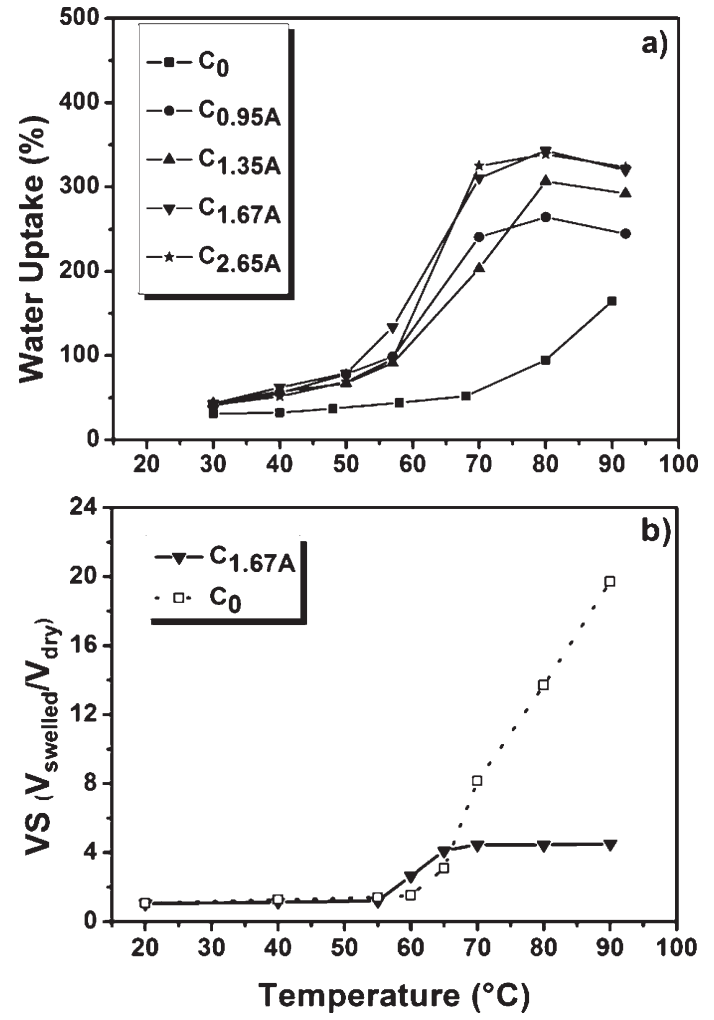

Figure 6. (a) Mass water uptake as a function of temperature for unfilled SPEEK $\left(C_{0}\right)$ and acid treated SPEEK/TNS composite membranes.

(b) Comparison of volume swelling as a function of temperature for $C_{0}$ and composite $C_{1.67 \mathrm{~A}}$.

smaller TNS contents $\left(C_{0.95 \mathrm{~A}}-C_{2.65 \mathrm{~A}}\right)$, the W.U. was stable and smaller than $100 \%$ up to a critical temperature, $T_{\text {CRIT }}$, around $60{ }^{\circ} \mathrm{C}$. When the temperature was increased above such $T_{\text {CRIT }}$, the W.U. of the reference membrane increased abruptly while that of the composites increased, reaching asymptotically larger values. Volume swelling (VS), expressed as the ratio between the volume of a swelled and that of a dry membrane, has been measured for samples $C_{1.67 \mathrm{~A}}$ and $C_{0}$. Figure $6 \mathrm{~b}$ shows the resulting data. VS follows the same trend of W.U., increasing sharply above $60{ }^{\circ} \mathrm{C}$ for the reference membrane and reaching stable values for the composite. The composite membrane remained flexible, showing at $70{ }^{\circ} \mathrm{C}$ a 2 -fold reduced VS, that at $90{ }^{\circ} \mathrm{C}$ was further reduced to almost $80 \%$ of the value measured for the unfilled SPEEK membrane. The formation of the composite modifies SPEEK properties producing samples characterized by improved dimensional stability.

In agreement with the widespread porosity observed in the SEM images of the composites with larger additive contents, such membranes were characterized by W.U. larger than $400 \%$ even at $T<60{ }^{\circ} \mathrm{C}$ (not shown), corresponding to an irreversible deformation and loss of dimensional stability. These latter membranes do not appear then suitable for use as electrolytes in fuel cells because their excessive swelling may cause mechanical failure during operation.

To evaluate the influence of the inorganic filler on the membranes electrochemical behavior, EIS measurements were performed on acid treated composites. Figure 7

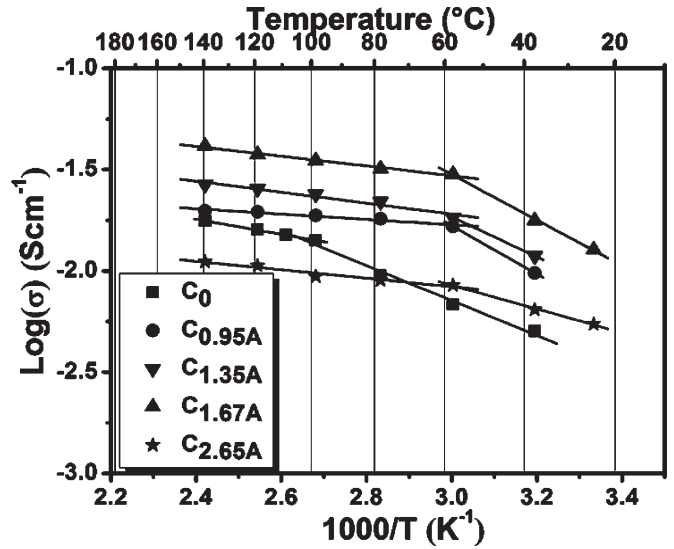

Figure 7. Conductivity plots as a function of temperature at RH $=100 \%$ for acid treated composites.

shows the Arrhenius plots of the composites at water saturated pressure conditions $(\mathrm{RH}=100 \%)$. Membranes $C_{0.95 \mathrm{~A}}-\mathrm{C}_{1.67 \mathrm{~A}}$ exhibited enhanced conductivity properties with respect to the reference $C_{0}$, whereas $C_{2.65 \mathrm{~A}}$, despite its larger P.E.C., was characterized by lower conductivity values at $T>60{ }^{\circ} \mathrm{C}$, probably as a consequence of arising porosity.

Two proton conducting regions were identified over the whole composite series, including the pure SPEEK membrane: a first one in the low temperature range characterized by activation energy, $E_{\mathrm{a}}$, between 0.19 and $0.12 \mathrm{eV}$, and a second one at higher temperatures, characterized by lower activation energy values $\left(E_{\mathrm{a}}=0.04-0.03 \mathrm{eV}\right)$. For the composite membranes, the transition from the first to the second region occurred at around $60^{\circ} \mathrm{C}$, whereas for pure SPEEK, the transition occurred around $100{ }^{\circ} \mathrm{C}$. Such transitions have been previously observed for different SPEEK-based membranes and have been attributed to structural changes in the swollen membranes, which modify the proton environment. The microstructural reorganization alters the size and connectivity of ionic clusters, creating different hydrophilic pathways for proton transfer, so that at high hydration levels, water becomes more loosely bound and conductivity eventually tends to bulk-like behavior. ${ }^{26,45}$ It is interesting to notice that, for the $C_{0.95 \mathrm{~A}}-C_{2.65 \mathrm{~A}}$ composites, both the increment in water uptake (Figure 6a) and the transition in proton conductivity occurred at $60{ }^{\circ} \mathrm{C}$. In contrast, the effect of larger amount of absorbed water in pure SPEEK membranes was found to be negligible for temperatures lower than $100{ }^{\circ} \mathrm{C}$. The $E_{\text {a }}$ values indicate that proton transport occurs through a Grotthuss mechanism, expected to be dominant at high hydration levels ${ }^{46-48}$

As a result of TBA substitution, the conductivity of the whole series of $C_{n \mathrm{TBA}}$ membranes was lower than that of

(45) Eikerling, M.; Kornyshev, A. A. J. Electroanal. Chem. 2001, 502,1.

(46) Colomban, P.; Novak, A. In Proton Conductors: Solids, Membranes and Gels Materials and Devices; Colomban, P., Ed.; Cambridge University Press: Cambridge, UK, 1992; p 38.

(47) Hogarth, W. H. J., Muir, S. S.; Whittaker, A. K.; Diniz da Costa, J. C.; Drennan, J. Lu, G. Q.(Max) Solid State Ionics 2007, 177, 3389 .

(48) Weber, A. Z.; Darling, R. M.; Newman, J. J. Electrochem. Soc. 2004, 151, A1715. 


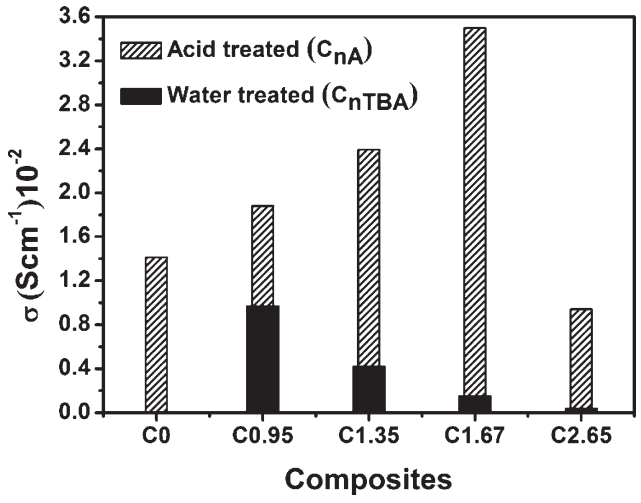

Figure 8. Conductivity values at $100{ }^{\circ} \mathrm{C}$ of water and acid treated membranes.

reference pure SPEEK membrane, in the whole range of investigated temperatures $\left(20-140{ }^{\circ} \mathrm{C}\right)$, in agreement with P.E.C. measurements. The lower amount of "free" acid functions on the polymer chain affects the pathway for proton transport subtracting sites for proton hopping through the electrolyte.

Figure 8 show the comparison between the proton conductivity values of the water $\left(C_{0.98 \mathrm{TBA}}-C_{2.65 \mathrm{TBA}}\right)$ and acid treated $\left(C_{0.95 \mathrm{~A}}-C_{2.65 \mathrm{~A}}\right)$ membranes at $100{ }^{\circ} \mathrm{C}$, which is a critical temperature for fuel cell operation, compared with that of the reference pure SPEEK membrane, $C_{0}$. The graph highlights a substantial enhancement of proton conduction for all the acid treated membranes, showing a maximum increment for $C_{1.67 \mathrm{~A}}$. The large differences observed in the electrochemical properties between the two different treated series of membranes confirmed the efficiency of the acid treatment in activating the proton conductivity by restoring the adequate amount of mobile protons.

The best performing membrane was $C_{1.67 \mathrm{~A}}$, which contains a rather low amount of TNS, exhibiting the largest proton conductivity $\left(\sigma=4.14 \times 10^{-2} \mathrm{Scm}^{-1}\right)$ at a temperature as high as $140{ }^{\circ} \mathrm{C}$. Although such enhancement is not so impressive when compared to the conductivity measured for pure SPEEK in the same experimental conditions $\left(\sigma=1.76 \times 10^{-2} \mathrm{Scm}^{-1}\right)$, the much lower VS of the composite membrane identifies it as a superior candidate for application as electrolyte in fuel cells.

Literature data about titania/polymer composites indicated $5 \mathrm{wt} . \%$ as the proper content of nanometric powder additives to obtain improved performance. ${ }^{13,49}$ The difference with literature data on nanometric titania powder can be accounted for the unique nature of TNS, characterized by a very large specific surface area and aspect ratio with respect to the three-dimensional spherical nanopowders. Typically, nanometric titania powders used for the preparation of nano composite electrolytes are characterized by experimental SSA values (determined by BET analysis) in the of $80-85 \mathrm{~m}^{2} / \mathrm{g}$ range

(49) Baglio, V.; Di Blasi, A.; Aricò, A. S.; Antonucci, V.; Antonucci, P. L.; Serraino Fiory, F.; Licoccia, S.; Traversa, E. J. New Mater. Electrochem. Syst. 2004, 7, 275. and $\mathrm{AR}=1,{ }^{13,50}$ whereas the measured AR of the TNS used in this work is ca. 7 and the estimated value for SSA is $735 \mathrm{~m}^{2} / \mathrm{g}$. The significantly larger AR and SSA values can be major discriminating factors in determining the extent of the interactions, thus altering the electrolyte properties. Moreover, the TNS peculiar properties could be also related to the surface polar sites (revealed by titration experiments), which appear to significantly interact with the chemical environment affecting the polymer-filler adhesion, improving the water retention characteristics and enhancing the proton conductivity. Consequently, the decrease in the inorganic additive content needed to obtain best performance could be associated to the enhancement of the nano inorganic filler surface properties for TNS-filled composites. Furthermore, the lamellar nano structures are supposed to considerably influence the pathway of the migrating species trough the membranes, thus affecting not only conductivity but also fuel crossover, acting as physical barriers.

\section{Conclusions}

A series of composite membranes were prepared by incorporation of titania nanosheets into SPEEK matrix, having a degree of sulfonation DS $=0.58$. Two preliminary treatment procedures were performed to remove additional components deriving from the TNS preparation method and to activate the membranes. The first one consisted in washing the membranes with water at room temperature, whereas the second was washing them with an acid solution. The acid treatment was required because water treated composites clearly showed a displacement of $\mathrm{H}^{+}$with $\mathrm{TBA}^{+}$on the sulfonic pendants, which led to $\mathrm{SO}_{3}$-TBA attached functions. Such substitution drastically affected the composite electrochemical properties resulting in a conductivity decrease with increasing the TBA amount.

However, a detrimental effect of the acid treatment was observed for the highly filled samples $\left(C_{5.33 \mathrm{~A}}\right.$ and $C_{10.00 \mathrm{~A}}$ ), which showed a porous morphology, excessive water swelling, poor dimensional stability, and inadequate electrochemical properties. On the other hand, acid treated membranes with a low content of TNS showed improved proton conductivity and water uptake properties with respect to pure $\operatorname{SPEEK}\left(C_{0}\right)$, due to the inorganic filler surface properties. TNS/SPEEK nanocomposites with very low filler content (1.67 wt. \%) are suitable for use as electrolytes for fuel cells working in the intermediate temperature range $\left(T>100^{\circ} \mathrm{C}\right)$.

Acknowledgment. This work has been supported by the Italian Ministry of Foreign Affairs (MAE) under the frame of the Italy-Japan Joint Laboratory on Nanostructured Materials for Environment and Energy. The valuable technical assistance of Ms. C. D'Ottavi is gratefully acknowledged.

(50) Marani, D.; Trakanprapai, C.; Licoccia, S.; Traversa, E.; Miyayama, M. In Materials Research Society Symposium Proceedings, S07-02T06-02, Warrendale, PA, 2009; p 1126. 